\title{
The Analysis Of Comments Received By The BIS On "Principles For Sound Liquidity Risk Management And Supervision"
}

Jacques Préfontaine, Université de Sherbrooke, Canada

Jean Desrochers, Université de Sherbrooke, Canada

Lise Godbout, Université de Sherbrooke, Canada

\begin{abstract}
The market turmoil that began in mid-2007 re-emphasized the importance of liquidity to the functioning of financial markets and the banking sector. In June 2008, the Basel Committee of the Bank for International Settlements (BIS) released a consultative document on Principles for Sound Liquidity Risk Management and Supervision. Interested parties were invited to provide written comments by the end of July 2008. As a result, the Committee received many comments for publication by 30 different commenters. Our analysis first indicates that comments were formulated on each of the 17 principles discussed in the consultative document. Second, comments were also made in each of the five separate defined areas of focus covered by the 17 principles. Third, the results of our analysis reveal that opinions on different principles differed the most when commenters were separated into four distinct categories: banking trade associations, regulatory supervisors, individual financial institutions, and others (consultants, academics, accounting associations, and financial information providers). Last but not least, the results of the study indicate that commenters' opinions, both within a category and between categories, differed the most in the two following defined areas of focus: measurement and management of liquidity risk and public disclosure of quantitative information on liquidity risk management.
\end{abstract}

Keywords: BIS, financial disclosure, FRB, liquidity risk, risk management, supervision

\section{INTRODUCTION}

$\mathfrak{J}$ he market turmoil that began in mid-2007 reiterated the importance of liquidity to the functioning of markets and the banking sector. In June 2008, the Basel Committee on Banking Supervision (BCBS) of the Bank for International Settlements (BIS) released a consultative document: "Principles for Sound Liquidity Risk Management and Supervision". Interested parties were invited to provide written comments by the end of July 2008. As a result, the BCBS received many comments in response to its (2008) consultation document. Thirty different commenters agreed to the fact that their position paper and views be made public on the BIS ${ }^{1}$ website.

Our analysis first examined if comments were formulated on each of the 17 principles discussed in the consultative document. The analysis also examined if comments were formulated on each of the five separate defined areas of focus covered by the 17 principles. In addition, the analysis also examined if the opinions expressed on different principles differed when commenters were separated into four distinct categories: banking trade associations, individual financial institutions, supervisors, and others (academics, accounting associations, consultants and financial information providers).

\footnotetext{
${ }^{1}$ Comments received on "Principles for Sound Liquidity Risk Management and Supervision" http://www.bis.org/publ/bcbs138/cacomments.htm?format=print
} 
The paper itself is structured as follows: Agency theory is presented in section two. Section two defines and examines the key liquidity risk management factors. It also discusses improved liquidity risk financial disclosure. The third section describes the research methods, the 30 commenters sample data, and formulates hypotheses on comments received by principle, by area of focus, and by category of commenters. Section four presents and discusses the study's empirical results. Finally, the conclusion limits of the study and suggestions for further research are drawn in the fifth section.

\section{IMPROVED FINANCIAL RISK MANAGEMENT THROUGH PUBLIC DISCLOSURE}

Gardner et al. (2005) discuss how Agency Theory, a positive view of managerial decision making helps explain how risk management decisions are actually made by financial institution managers rather than prescribing how they should be made. In their view, Agency Theory implies that financial institutions' managers set financial risk management objectives and determine estimates of potential losses that could result from their business activities. While owners and their delegated monitors (regulators, credit rating agencies, financial analysts...) protect their interests by setting appropriate risk management constraints and financial disclosure standards and requirements.

Recent empirical work by the BCBS and the Joint Forum support the view that the level and extent of financial groups' liquidity risk management public disclosure are not satisfactory. Our research, Boussanni et al. (2007, 2008) examined the informational content and the usefulness of financial groups' liquidity financial disclosure. The results of the study are based on an in-depth content analysis of the annual reports (2004) published by twenty-one of Europe's largest financial groups using the key liquidity risk management factors (KLF) proposed by the BCBS and its Joint Forum $(2003,2006)$. The results of the study revealed a wide disparity in the level and extent of liquidity risk financial disclosures between financial groups from the same or different European countries. For most of the ten KLFs, the scores obtained on the level and extent of qualitative discussions were higher than those relating to quantitative illustrations of the same KLF. The most complete qualitative discussions and the most substantive quantitative illustrations were provided for the three following KLFs: measuring and monitoring net funding requirements (KLF 2) and foreign currency liquidity management (KLF 5) as well as coverage of the origins of cash flows (KLF 9). Conversely, the level and extent of financial disclosures were found to be the least complete and the least substantive in the following three KLFs: contingency planning (KLF 4), internal controls for liquidity management (KLF 6) and explaining and illustrating the role of public disclosure in improving liquidity (KLF 7). Finally, the results of the study showed that financial groups that have earned a relatively high (low) credit rating category were also the institutions that made the most (least) complete and extensive, both qualitative and quantitative, liquidity risk management financial disclosures. In most aspects, these results lend support to the principles formulated in the present BCBS paper.

\section{EXAMINING THE COMMENTS RECEIVED BY THE BIS ON "PRINCIPLES FOR SOUND LIQUIDITY RISK MANAGEMENT AND SUPERVISION"}

The objective of this paper is to carry out an analysis of comments received by the BIS on its consultative document on "Principles for Sound Liquidity Risk Management and Supervision". The result of the analysis will be based upon an in-depth content analysis of thirty commenters' position paper who agreed to the fact that their position paper and views be made public by the BIS. The BIS consultative document (June, 2008) was a 36 page document which structured the topic of "Sound Liquidity Risk Management and Supervision" into five areas of focus and seventeen principles in total.

The results of the analysis will attempt to answer the following four research questions:

Question 1: Question 2: Question 3:

Question 4:
Which of the five areas of focus were more widely discussed by commenters?

Which of the seventeen principles were more widely discussed by commenters?

How does regrouping commenters into four district affinity groups influence their choices of areas of focus and principles that were discussed?

In which of the five areas of focus and seventeen principles were commenters' opinions more strongly divergent? 
In order to facilitate the discussion and analysis of the BCBS (June 2008) draft for consultation, the five areas of focus and 17 principles are presented in Table 1 in the text.

In addition, to facilitate the discussion and analysis of the results of this study, the 30 commenters are presented by affinity group in Table 2 .

Table 1: Principles for Sound Liquidity Risk Management and Supervision: Areas of Focus (5), Principles (17)

1. Fundamental principle for the management and supervision of liquidity risk: Principle 1

2. Governance of liquidity risk management: Principles 2,3 and 4

3. Measurement and management of liquidity risk: Principles 5, 6, 7, 8, 9, 10, 11 and 12

4. Public disclosure: Principle 13

5. The Role of Supervisors: Principles 14, 15, 16 and 17

Source: Basel Committee on Banking Supervision, (June 2008), pp. 3-5.

As shown in Table 2, sixteen commenters belonged to the Financial services industry associations' group, three commenters were placed into the Supervisors' group, five commenters fell into the Financial institutions' group, and six remaining commenters were placed into the Others' group.

As a matter of interest, commenters' position papers averaged about six pages in length. If commenters are divided into affinity groups, Financial services associations (6.6 pages) and Others (6.8 pages) presented much longer papers than Financial institutions (5 pages) and Supervisors (3.3 pages).

Table 2: Commenters (30) - Listed by Affinity Group (4)

\section{Financial services industry associations (16):}

Canadian Bankers Association, European Association of Co-operative Banks, European Association of Public Banks, European Savings Banks Group, Febelfin, French Banking Federation, International Bk.Fed., IMMFA, Institute of International Finance, Italian Banking Association, Japanese Bankers Association, Mortgage Insurance Companies of America, Netherlands Bankers Association, UK Joint Trade Association (BBA, ISDA and LIBA), World Council of Credit Unions, Zentraler Kreditausschuss.

2. Supervisors (3):

Central Bank of Brazil, IOSCO Standing Committee 3, Reserve Bank of New Zealand.

3. Financial institutions (5):

Credit Suisse, Dexia, Royal Bank of Scotland, UniCredit Group, US Bankcorp.

4. Others (6):

Clearing House, Fielder and Maltz, Independent Audit Limited, Institute of Chartered Accountants of England and Wales, Thomson Reuters, University of Sherbrooke.

Source: http://www.bis.org/publ/bcbs138/cacomments.htm

\section{THE EMPIRICAL RESULTS}

The purpose of this section is to present and more closely examine the empirical results identifying the Principles, the areas of focus discussed by all commenters in general, and also commenters listed by affinity group. The results of the analysis will be presented in four parts each of which addressing one of the four previously formulated research questions.

\subsection{Areas of Focus more Widely Discussed by Commenters}

If we consider the total sample composed of thirty commenters, it can be observed in Table 3 that the First Principle area of focus was discussed by all commenters with no exception. The second most discussed area of focus was Public Disclosure with twenty-five commenters. Sixteen commenters on average discussed the Measurement and Management of Liquidity Risk area of focus. The Role of Supervisors area of focus was discussed by fourteen commenters on average. Only twelve commenters on average discussed the principles involved with the Governance of Liquidity Risk Management. 


\subsection{Principles more Widely Discussed by Commenters}

If we consider the total sample composed of 30 commenters, the results displayed in Table 3 seem to corroborate the fact that the most (least) widely discussed liquidity risk management principles also fall into the most (least) widely discussed liquidity risk management areas of focus. In order to more clearly present this form of analysis, Table 4 in the text identifies the six principles that were most (six least) often discussed by all commenters. For example, the three most widely discussed principles were: Principle 1, The Fundamental Principle, which defines the principles-based approach adopted in the BCBS consultation draft; Principle 13, Public Disclosure, exposed the need for liquidity risk management publicly disclosed information; and lastly, Principle 17, Role of Supervisors, exposed the need for communication and cooperation between home and host country supervisors. Similarly, as also shown in Table 4, principles 9, 16, 2 and 15 were identified as being the four principles least often discussed by commenters.

Table 3: Identification of the Principles Discussed by Commenters - Listed by Affinity Group

\begin{tabular}{|c|c|c|c|c|c|}
\hline $\begin{array}{c}\text { Principle } \\
\text { (Area of Focus) }\end{array}$ & $\begin{array}{c}\text { Financial Services } \\
\text { Industry Associations } \\
(16)\end{array}$ & $\begin{array}{c}\text { Supervisors } \\
\text { (3) }\end{array}$ & $\begin{array}{c}\text { Financial } \\
\text { Institutions } \\
(\mathbf{5}) \\
\end{array}$ & $\begin{array}{l}\text { Others } \\
\text { (6) }\end{array}$ & $\begin{array}{c}\text { Total } \\
\text { (30) }\end{array}$ \\
\hline 1. $\quad$ FP & $16^{*}$ & $3 *$ & $5^{*}$ & 6* & $30 *$ \\
\hline 2. GLRM & 4 & 1 & 2 & $3 *$ & 10 \\
\hline 3. & 3 & 1 & $4 *$ & $5^{*}$ & 13 \\
\hline 4. & $8 *$ & 0 & 2 & $4 *$ & 14 \\
\hline 5. MMLR & $11 *$ & 1 & $4 *$ & 2 & $18^{*}$ \\
\hline 6. & 7 & 1 & $4 *$ & 2 & 14 \\
\hline 7. & 7 & 1 & $4 *$ & 1 & 13 \\
\hline 8. & $11^{*}$ & 0 & $4 *$ & 2 & $17 *$ \\
\hline 9. & 5 & 1 & $4 *$ & 1 & 11 \\
\hline 10. & $10 *$ & 1 & $4^{*}$ & $5 *$ & $20 *$ \\
\hline 11. & $8^{*}$ & $2 *$ & $3 *$ & $4 *$ & $17 *$ \\
\hline 12. & $9 *$ & 1 & $3 *$ & $5 *$ & $18^{*}$ \\
\hline 13. PD & $12 *$ & $3 *$ & $5 *$ & $5 *$ & $25^{*}$ \\
\hline 14. ROS & 6 & $2 *$ & 2 & $4 *$ & 14 \\
\hline 15. & 5 & $2 *$ & 1 & 2 & 10 \\
\hline 16. & 6 & 1 & 1 & $3 *$ & 11 \\
\hline 17. & $11^{*}$ & $2 *$ & $3 *$ & $5 *$ & $21 *$ \\
\hline
\end{tabular}

Fundamental

FP:

GLRM:

MMLR:

PD:

ROS:

Fundamental Principle (30/30)

Governance of Liquidity Risk Management (12.3/30)

Measurement and Management of Liquidity Risk (16/30)

Public Disclosure (25/30)

* Discussed by at least $50 \%$ of the subsample, or of the total sample (30).

\subsection{Areas of Focus and Principles more Widely Discussed by Commenters Listed by Affinity Group}

Turning back to the results shown in Table 3, it can be observed that the Financial Services Industry Associations affinity group commenters most often discussed the Fundamental Principle (principle 1) area of focus, the Public Disclosure (principle 13) area of focus, and the Measurement and Management of Liquidity Risk (principles 5, 8, 10, 11 and 12). Second, the supervisors affinity group preferred areas of focus were: The Fundamental Principle (principle 1), Public Disclosure (principle 13), and most importantly the Role of Supervisors (principles 14, 15 and 17). Third, the financial institutions affinity group preferred areas of focus were: The Fundamental Principle (principle 1) as well as Public Disclosure (principle 13), also Measurement and Management of Liquidity Risk (principles 5 to 12 inclusively). Finally, the others affinity group preferred areas of focus were: The Fundamental Principle (principle 1) as well as Public Disclosure (principle 13). In addition commenters from the others affinity group very widely discussed the Governance of Liquidity Risk Management area of focus (principles 2, 3 and 4), the Measurement and Management of Liquidity Risk (principles 10, 11 and 12), and finally the Role of Supervisors area of focus (principles 14, 16 and 17). 


\subsection{Areas of Focus and Principles in which Commenters' (Listed by Affinity Group) Opinions are more Strongly Diverged}

All commenters agreed that a principle-based approach was well adapted to the management and supervision of liquidity risk. However, both individual financial institutions and their trade associations commenters' expressed a strong preference for more flexibility in the application of the 17 principles. Their arguments reflected a strong bias in favour of proportionality and materiality arguments.

Table 4: Identification of the Six Principles Most (Least) Often Discussed by Commenters

\begin{tabular}{cllc}
\hline Principle & Theme & Explanation & Total (30) \\
\hline 1. & Fundamental Principle & Principles-based approach & $30^{*}$ \\
\hline 13. & Public Disclosure & Publicly disclosed information & $25^{*}$ \\
\hline 17. & Role of Supervisors & Communication, cooperation & $21^{*}$ \\
\hline 10. & Measurement and Management of Liquidity Risk & Conduct of stress tests & $20^{*}$ \\
5. & & Liquidity risk management process & $18^{*}$ \\
12. & & Liquidity Cushion & $18^{*}$ \\
\hline 3. & Governance of Liquidity Risk Management & Strategy, policies, and practices to manage & 13 \\
& & liquidity risk & 13 \\
\hline 7. & Measurement and Management of Liquidity Risk & Funding strategy & 11 \\
\hline 1. & & Collateral positions & 11 \\
\hline 2. & Role of Supervisors & Intervention & 10 \\
\hline 15. & Governance of Liquidity Risk Management & Liquidity risk tolerance & 10 \\
\hline
\end{tabular}

*Discussed by at least $60 \%$ of the commenters.

In the Governance of Liquidity Risk Management area of focus, financial institutions and their trade associations agreed with principle 2 that stated that a bank should articulate a liquidity risk tolerance; however, it need not be disclosed publicly. In the focus area of Measurement and Management of Liquidity Risk, both financial institutions and their trade associations' commenters argued that a bank should centrally manage liquidity risk exposure and funding needs at the group level. As for principle 10, they argued that a bank should carry out stress tests, but that the results should not be publicly disclosed. Financial institutions and their trade associations agreed to principle 11 on the formulation of a contingency funding plan that did not lead to building-up an excessive liquidity cushion. This cushion described in principle 12 would be formed of unemcumbered, and high quality assets. Again, these commenters believed that the size and exact composition of this liquidity cushion should not be publicly disclosed. In the Public Disclosure area of focus (principle 13), most individual financial institutions and their trade associations agreed with the BCBS formulation that a bank should publicly disclose information on a regular basis that enables market participants to make informed judgment about the soundness of its liquidity risk management framework and liquidity position. However, individual institutions and their trade associations believed that the present level and extent of qualitative and quantitative publicly disclosed information was satisfactory. Nevertheless, more complete and perhaps staggered information could be disclosed to supervisors and credit rating agencies. In the focus area covering the Role of Supervisors, individual institutions and their trade associations again presented the most diverging views. In principle 14, they requested that supervisors more clearly define their role in firm-only extreme liquidity events and also in market-wide extreme liquidity events. In principle 15 , following the comply-orexplain doctrine, they expressed the view that supervisors make more intense use of banks' internal liquidity risk management reports as opposed to one format-only prudential reports. In principle 16, the BCBS argued that supervisors should intervene to require effective and timely remedial action (usually in the form of higher capital adequacy requirements). Financial institutions and their trade associations argued that capital is a poor substitute for inadequate liquidity; however, they did not suggest any satisfactory alternative. In closing, financial institutions and their trade associations agreed with the essence of Principle 17 saying that supervisors, both home and host country, should more closely communicate and cooperate within and across national borders. In addition, they favour designating a lead supervisor, the mutual recognition of home-host country supervisors and other measures designed to facilitate the role of a college of supervisors. 


\section{DISCUSSION AND CONCLUSION}

This paper carried out an analysis of written comments received by the BIS on its consultative document on "Principles for Sound Liquidity Risk Management and Supervision". The results of the analysis are based upon an in-depth content analysis of 30 commenters' separate position paper who agreed that their views be made public. As an answer to the first research question formulated in section 3 of this paper, the analysis showed that the Fundamental Principle and Public Disclosure areas of focus were widely discussed by a great majority of commenters. Measurement and Management of Liquidity Risk was discussed by a majority of commenters and Governance of Liquidity Risk Management and Role of Supervisors by less than a majority of participants. The second research question was answered by identifying which of the 17 Principles were most often discussed by commenters. The analysis revealed that at least $60 \%$ of all commenters discussed Principle 1 (the fundamental principle), Principle 13 (publicly disclosed information), Principle 17 (communication and cooperation), Principle 10 (conduct of stress tests), Principle 5 (liquidity risk management process), and Principle 10 (liquidity cushion). By studying results of the affinity group, it was possible to observe that Financial services industry associations and individual financial institutions most often formulated similar comments on the three following areas of focus: Fundamental principle, Public disclosure, and Measurement and Management of Liquidity Risk. Supervisors most often discussed the First Principle and the Public Disclosure areas of focus; naturally, they also focused their comments on many aspects of the Role of Supervisors. As for the Others affinity group, the results indicated a relatively wider range of areas of focus in addition to Fundamental Principle and Public Disclosure. By answering the first three research questions, it was then possible to provide an answer to the fourth research question. Both Financial services industry associations and Individual financial institutions were found to be the two affinity groups whose opinions more strongly diverged than those expressed in the BCBS consultative document itself and by the Supervisors and Others affinity groups. Both individual financial institutions' and their trade associations' commenters expressed a strong preference for more flexibility in supervisory oversight in the application of the 17 principles. Constructive comments were also formulated in each of the five areas of focus; most notably in the area of Measurement and Management of Liquidity Risk. It was also revealed, by comparisons with all affinity groups, that financial institutions and their trade associations did not agree with the proposition formulated in principle 13 (Public disclosure) to increase the present level and extent of liquidity risk management public disclosure, especially quantitative public disclosure that pertained to risk metrics now widely used within the financial services industry.

\section{ACKNOWLEDGEMENT}

Financial support from the Desjardins chair in sustainable development is gratefully acknowledged.

\section{REFERENCES}

1. Basel Committee on Banking Supervision, Final report, 2008. "Principles for Sound Liquidity Risk Management and Supervision.” Bank for International Settlements (September).

2. Basel Committee on Banking Supervision, Draft for consultation, 2008. "Principles for Sound Liquidity Risk Management and Supervision.” Bank for International Settlements (June).

3. Basel Committee on Banking Supervision, The Joint Forum, 2006. "The Management of Liquidity Risk in Financial Groups.” Bank for International Settlements (May).

4. Basel Committee on Banking Supervision, The Joint Forum, 2004. "Financial Disclosure in the Banking, Insurance and Securities Sectors: Issues and Analysis." Bank for International Settlements (May).

5. Basel Committee on Banking Supervision. 2003b. "Public Disclosures by Banks: Results of the 2001 Disclosure Survey.” Basel Committee Publications No. 97 (May).

6. Board of Governors of the Federal Reserve System. 2000. "Improving Public Disclosure in Banking." Staff Study \# 173.

7. Boussanni, A., Desrochers, J., Préfontaine, J. (2008). "Liquidity Risk Financial Disclosure: The Case of Large European Financial Groups.” International Business \& Economics Research Journal, Vol. 7(7), July 2008.

8. Committee of European Banking Supervisors, 2008. "Consultation Paper CP 19 on Liquidity Risk Management." CEBS, (July) 
9. Desrochers, J. Préfontaine, J. (2008). "Principles for Sound Liquidity Risk Management and Supervision." Basel Committee on Banking Supervision, Working Group on Liquidity, Bank for International Settlements, July 2008, pp. 1-8.

10. Horton, J. 2007. "The Value Relevance of 'Realistic Reporting': Evidence from UK Life Insurers." Accounting and Business Research, vol. 37(3), pp. 175-197.

11. Institute of International Finance, 2007. "Principles of Liquidity Risk Management." IIF, (March).

12. Jorion, P. 2002. "How Informative Are Value-at-Risk Disclosures?" The Accounting Review 77, pp. 911931.

13. Kwan, Simon H. 2002. "Bank Security Prices and Market Discipline.” FRBSF Economic Letter 2002-37 (December 20).

14. Kwan, Simon H. 2006. "Safe and Sound Banking, 20 Years Later.” FRBSF Economic letter 2006-26 (October 6).

15. Liu, C.C., Ryan, S.G., Tan, H. 2004. "How Banks' VaR Disclosures Predict their Total and Priced Risk." Review of Accounting Studies 9 (June-September), pp. 265-294.

16. Lopez, Jose A. 2004. "Supervising Interest Rate Risk Management." FRBSF Economic Letter 2004-26 (September 17).

17. Lopez, Jose A. 2003. "Disclosure as a Supervisory Tool: Pillar 3 of Basel II.” FRBSF Economic Letter 2003-22 (August 1).

18. Préfontaine, J., Desrochers, J., Godbout, L., 2009. "The Informational Content of Voluntary Embedded Value (EV) Financial Disclosures by Canadian Life Insurance Companies”. Best paper award and accepted for publication, European Applied Business Research Conference, Prague, Czech Republic (June).

19. Préfontaine, J., Desrochers, J., Kadmiri, O. 2006a. "How Informative Are Banks' Earnings-at-Risk and Economic Value of Equity-at-Risk Public Disclosures?” Insurance and Risk Management, vol. 74 (1), April, 1-19.

20. Préfontaine, J., Houde, D., Desrochers, J., Martel, D. 2006b. “The Informational Content of the VaR Measures Associated with the Trading Activities of Canadian Banks". International of Business and Economics Research Journal.

21. Sierra, G. E., Yeager, T. J. 2004. "What Does The Federal Reserve's Economic Value Model Tell Us About Interest Rate Risk at U.S. Community Banks?” Review 86, FRBSL (Nov./Dec.), pp. 45-60. 


\section{NOTES}

